\title{
Citation:
}

Burgess R., Mathias K. (2017) Community Mental Health Competencies: A New Vision for Global Mental Health. In: White R., Jain S., Orr D., Read U. (eds) The Palgrave Handbook of Sociocultural Perspectives on Global Mental Health. Palgrave Macmillan, London. https://doi.org/10.1057/978-1-137-39510-8_11

\section{Community mental health competencies: A new vision for global mental health}

Rochelle Burgess, $\mathrm{PhD}$

Centre for Primary health and Social Care, London Metropolitan University

Health, Community and Development Research Group, London School of Economics

Kaaren Mathias, MBChB, MPH, FNZCPHM

Emmanuel Hospital Association, New Delhi and Centre for Epidemiology and Global Health, University of Umeå

\begin{abstract}
:
As part of the Movement for Global Mental Health's (MGMH) efforts to scale-up services, attention has shifted to the level of communities, with community engagement recognised as a key locus of action to promote treatment and rehabilitation. Communities have long been viewed as key mediators in the management of health. However, the multifarious nature of what we mean by the term 'community' makes the promotion of mental health through action at this level a process that is endlessly complex, and demanding of further exploration. This chapter aims to elaborate on the validity of community mental health competency (Campbell \& Burgess, 2012) as a conceptual framework to guide community engagement for global mental health practice. The chapter draws on case studies from two different settings each pointing to the value of various dimensions highlighted by the approach. The studies highlight that through a focus on promoting constructive partnerships, critical dialogue, valuing local knowledge, and promoting safe spaces, mental health services can be brought in line with the varied local realities that shape communities around the world.
\end{abstract}




\section{Introduction}

This chapter takes interest in defining the notion of 'community' within global mental health. Specifically, it seeks to elaborate on the psychosocial processes that enable the promotion of mental health in an era where 'community level' responses form the core of treatment approaches (see Hanlon et al., 2010; WHO 2010). It argues that 'community engagement' for mental health is a concept largely unexplored and narrowly conceptualised, with serious implications for service outcomes. It is widely argued that 'community approaches' must be locally grounded. To achieve such ends, action that extends beyond the scope of most psychosocial forms of community interventions is required ( Burgess, 2014; Campbell \& Cornish, 2010). This chapter presents two brief case studies exploring multiple approaches to the idea of 'community' mental health from around the globe. It highlights the opportunities and challenges presented by a 'community mental health competency' approach, anchored in a perspective where community voices and realities actively shape responses and enable communities to become self-determining agents of their own mental wellbeing.

\section{Background}

Mental, neurological and substance abuse disorders have been identified as the largest contributors to years lost to disability globally (Whiteford et al., 2013). In low and middle income country (LMIC) settings where mental health spending averages less than 25 cents per person (WHO, 2011), more than $85 \%$ of mental health conditions go untreated (Saxena, Thornicroft, Knapp, \& Whiteford, 2007). Outcomes for individuals with mental distress are further complicated by the absence of legislation to protect their human rights - with only $36 \%$ of individuals in LMIC settings protected under mental health legislation (WHO, 2013).

Amidst a climate of austerity in both high and LMIC settings, interventions promoting empowerment and local action in response to health problems has become increasingly popular (Lowndes \& Pratchett, 2012), often idealising communities as spaces of potential, shared identity and common ideals (Campbell, 2003). However, these perspectives can often gloss over the complexities of promoting community engagement - an issue that has been explored extensively in the contexts of community responses to HIV/AIDS in sub-Saharan Africa. For example, the invisible dimensions of power, position, norms, and conflicting knowledge systems, have all been linked to the challenges facing community work within the 
HIV/AIDS response (Campbell, Gibbs, Maimane, \& Nair, 2008; Campbell \& Nair, 2014; Campbell, 2000; Gibbs \& Campbell, 2014; Burgess, 2013). Potential impacts of these issues bear relevance beyond HIV/AIDS, and carry implications for any health issue being tackled at community level (Campbell \& Cornish, 2010).

The expansion of a community discourse in the field of global mental health has been driven largely by the Movement for Global Mental Health (MGMH) (See Patel \& Prince, 2010), whose main interest resides in addressing the gap between the proposed need for treatment and available services in low LMIC. Their interest in communities has been linked to community approaches piloted during the first two decades of the AIDS response (Campbell \& Burgess, 2012), and the wider movement of deinstitutionalistion of mental health services in the 60's and 70s in many high income country settings. Capacitating local communities to promote self-care through promoting volunteerism and training of lay community health workers has assumed the core of the community engagement framework within global mental health. The publication of a series of grand challenges for global mental health (Patel, Boyce, Collins, Saxena, \& Horton, 2011) confirmed the importance of communities to the movement with two 'challenges' explicitly naming 'community' as a locus of action:

\section{Provide effective and affordable community-based care and rehabilitation.}

2. Support community environments that promote physical and mental well-being throughout life

Community-based care and rehabilitation has formed the focus of multiple studies and research to identify 'cost effective' mental health interventions (Patel and Thornicroft, 2011) delivered by community volunteers and health professionals under the umbrella of 'taskshifting' approaches (Kakuma et al., 2011). In this model, community health workers are trained in basic treatment skills to act as appendages to over-burdened or non-existent health systems. Health volunteers are hoped to act as trusted conduits, smoothing relations and the uptake of ideas among local individuals. The second point - promoting supportive community environments speaks more directly to ideas of social change - and efforts to ensure that communities (local environments) are places where positive mental health can be maintained.

Theoretically, community-based approaches allow for attention to a wider range of determinants of mental ill-health and related responses, which could contribute positively to 
addressing both of the above 'grand' challenges facing the movement. However, given issues faced with implementing community approaches in other health settings (Campbell, 2003) how do we develop approaches to 'community' mental health in a global context?

\section{Defining 'community'}

In order to trace the complexities facing 'community mental health' one must acknowledge limitations of the term 'community' itself. Traditional social science debates about the concept cut across multiple fields: making the term inherently plural, fluid and malleable, with practical, symbolic and rhetorical weight (Howarth, Cornish and Gillespie, 2013).

Community typically conjures the image of a coherent (and often positive) grouping of individuals, united by a common factor that shapes the identity of each member in some way. The term describes groups of individuals united by characteristics such as location, shared practices and values (i.e. a profession), common experiences (racism/exclusion), interest (i.e. a hobby), culture, religion, or physical characteristics, such as a health diagnosis (Howarth, 2001). These categories can be organised into two broad camps - communities linked to tangible structures, such as spatial dimensions, and those linked to 'symbolic' and intangible dimensions, such as identity, or cultural norms.

Community ultimately gains meaning though the value the categorical label holds to someone's every day survival (Cohen, 1985). In this sense, structural dimensions of community - such as areas of space are equally important as symbolic dimensions and are often inseparable. For example, participation in cultural celebrations such as birth celebrations, cannot be divorced from the structural dimensions of spatial communities where a cultural practice is lived. The availability of services, quality of housing, and economic opportunities available within a community, exert forces on the ability to participate in a cultural celebration, with meaningful impacts in one's life.

Individuals often hold memberships to multiple 'communities' at any given time and can accept or reject membership based on the importance of a community identity (Howarth, 2001; Jovchelovitch, 2007). Thus we could better think of people as 'living' community through their actions, relationships, and other forms of social participation - a perspective that is often absent from community health approaches. In fact, it is perhaps more useful to view any single community as an interactive space - one where the realities of any one community blend into and influence the reality and outcomes of others (Burgess 2013). 
However, the fluidity of the term also makes it open to co-option, particularly among political platforms, who invoke the term to serve different and sometimes contradictory ideals. For example, successive British Governments' use of the concept anchors to the belief that 'communities' are self-sustaining, able to improve themselves in spaces outside of state support (Fremeaux, 2005). Conversely, the term is also linked to highlighting the plight of 'at-risk' and 'excluded' communities who must be targeted for special support and resources in order to tackle inequality (Allen, Balfour, Bell \& Marmot, 2014).

In light of such controversies, engagement with community will involve attention to the making and shaping of meaning, which is in turn, influenced by social forces and power relations between groups. What are the implications of this 'plurality' for community interventions that seek to address mental-ill health?

\section{Addressing community mental health: a moving target?}

The classical position assumed in community mental health across low and high resource settings foregrounds community of place. In North America, this is driven by the legacy of deinstitutionalisation with group homes, nursing homes and other neighbourhood settings where patient care often occurs (Knapp, Beecham, McDaid, Matosevic, \& Smith, 2011). Community case managers often coordinate multiple health and social care services for mental health clients with complex needs, often without equal attention to social challenges such as poverty, unemployment, criminalisation and violence (Kleinman, 1988). Individuals often oscillate between acute hospital settings and incarceration, while many struggle with homelessness or settings that exacerbate experiences of mental distress, rather than resolve them (Weinstein et al., 2013).

In African and other low income country settings, resource limitations and a lack of mental health policies have limited the availability of community mental health care services. Trials of community-based services in some countries date back to 1960s and 1970s, where, in line with de-institutionalisation movements elsewhere, emphasis was placed on treating individuals within community spaces. While many countries continue to over rely on institutional settings, there has been a shift towards the provision of mental health within primary care on the continent (Hanlon, Wondimagegn, \& Alem, 2010). Current 'community approaches include a range of interventions, such as integrated primary mental health care that link mental health services to existing primary care clinics and programmes, which are increasingly popular in LMIC settings (Petersen et al., 2009). 
From a pragmatic position, communities bounded by space are an inescapable dimension for health services. Across districts, provinces, or neighbourhoods, health practitioners are allocated based on population levels. As such, attention to communities of 'place' in of itself is not limiting, as place driven realities are known to exert boundaries on the possible realities for social outcomes (Gerard \& Duveen, 1991). For example, poverty, violence, and unemployment contribute to mental health outcomes, making the achievement of wellbeing more or less likely in settings shaped by such factors Ultimately it is the prioritization of community as place over other forms of community that emerges as problematic (Campbell \& Cornish, 2010).

Increasingly mental health supports have attempted to engage with broader community issues of culture, power, knowledge and identity, which are key psychosocial determinants of mental well-being (Keyes 1998; Burgess and Campbell, 2014). For example, a 2012 special issue on community mental health in Australia acknowledged the importance of viewing community at the level of space (environmental infrastructure), place (sociohistorical dimensions of community) and people (attention to the skills and capabilities of individuals) to the promotion of mental health in low-income communities (Rose and Thompson, 2012). Furthermore, community psychology approaches aim to promote justice and social change in communities through attending to the interplay between symbolic (i.e. identity) and structural (i.e. poverty, systems of governance) aspects of community and their related impacts on health within the space of interventions (Nelson and Prilletensky, 2010).

However current WHO and MGMH discourses driving research and action frameworks for mental health practice tend to emphasise community engagement in relation to the pragmatics of bio-psychosocial services, assuming community homogeneity in the process of prioritising spatial dimensions above other issues (Campbell \& Burgess, 2012; Patel \& Prince, 2010; Summerfield, 2008). For example, a recent study exploring the foundations for integrated mental health care in five low-income countries (Hanlon et al., 2014) asserts the importance of 'community' interventions such as adherence support, screening, and community-based psychosocial prevention. While the authors also reference the importance of multi-sectorial collaboration to tackle broader social issues such as housing, this is linked to individual plans for recovery rather than attention to tackling wider social environments that contribute to mental distress in equally significant ways (Fullagar \& O’Brien, 2014). 
The success of global mental health approaches would likely be accelerated by eschewing the current emphasis on the pragmatics of services in favour of promoting more meaningful engagement with communities (Campbell \& Burgess, 2012; Kirmayer \& Pedersen, 2014; Swartz, 2012). To achieve this, frameworks that integrate attention to short term treatment and recovery issues, with wider social determinants of mental health are needed.

\section{Community mental health competencies - a flexible framework for community mental health}

Recent work by the first author of this chapter (Burgess 2012; Campbell and Burgess, 2012; Burgess 2013; Burgess 2014) articulates the value of critical community psychology frameworks in grappling with the complex nature of community and a wider range of sociostructural determinants of mental health. The community mental health competency framework (Burgess, 2012; Campbell \& Burgess, 2012) begins with a reconceptualization of 'community' for mental health. In this framework, mental health services are positioned as the meeting place of multiple communities, which are often linked to varied approaches to mental ill-health (Kleinman 1980; Swartz 1998). These symbolic and relational communities are then viewed within the context of a shared community of place, in order to account for the impacts of social and structural factors on service outcomes. This enables tangible impacts of poverty, violence, unemployment, and a range of other social challenges that characterise many communities around the world to be seen as active factors that shape the lived experience and understandings of community members (Summerfield, 2008; 2012). This is particularly important given that LMIC settings are marked by such characteristics.

Another important feature of the community mental health competency approach is the emphasis on Partnerships. Bourdieu (1986) argues that attention to different forms of social capital are critical to health, as access to social, cultural and economic capital may open pathways to resources that may mediate health risk. Partnerships are viewed as routes to increasing access to these forms of capital. Similarly, Putnam (2000) suggests that social capital provides ties within communities that enable access to necessary structural and symbolic resources. Bridging social capital is one example of such partnerships, which build ties to agents outside of a particular community with access to alternative and needed resources. Within the proposed framework, programmes are viewed as opportunities to strengthen existing partnerships, or establish new ones, with communities, with a view to establishing links to resources beyond those that already exist. Partnership building is 
supported through quality communication between actors in line with Habbermas's (1984) concept of communicative action - where both groups are engaged in a communicative encounter that drives towards both actors being heard. In many instances, promoting such communicative encounters will requires attention to the development of safe spaces, where traditionally excluded voices have the opportunity to be heard (Fraser, 1990).

In order to continually foreground structural community drivers of distress, the framework suggests that programmes should also seek to foster resources that enable communities to identify and engage with issues they deem problematic, which are often shaped by economic and political processes beyond local control (Campbell \& Mamaine, 2007). This engagement should occur alongside addressing mental health needs, and involve engagement with members from various sub-groups of a community (i.e. - treatment groups, families, members from the wider community, practitioners). All sub-groups should be viewed as agents and partners with important knowledge that contributes to the promotion of well-being. By taking these factors into account during initial planning stages, interventions are thus designed with the aim to expand the knowledge of groups and increasing local strength and capacity for change.

The competencies for community mental health introduced in Table 1 below emerged through research into community mental health services in South Africa conducted in 2008 2011 by the first author (see Burgess 2012; Burgess 2013). Each of the four principles were identified as psycho-social resources key to the promotion of spaces where mental health issues can be addressed in locally sensitive and relevant ways, alongside efforts to tackle wider determinants of distress.

\begin{tabular}{|c|c|}
\hline Knowledge & $\begin{array}{l}\text { Enhances the ability of communities to } \\
\text { identify and refer serious cases of mental } \\
\text { ill health and respond to others in } \\
\text { culturally appropriate manner } \\
\text { - Supports the acceptance of cultural and } \\
\text { social narratives among professionals }\end{array}$ \\
\hline
\end{tabular}




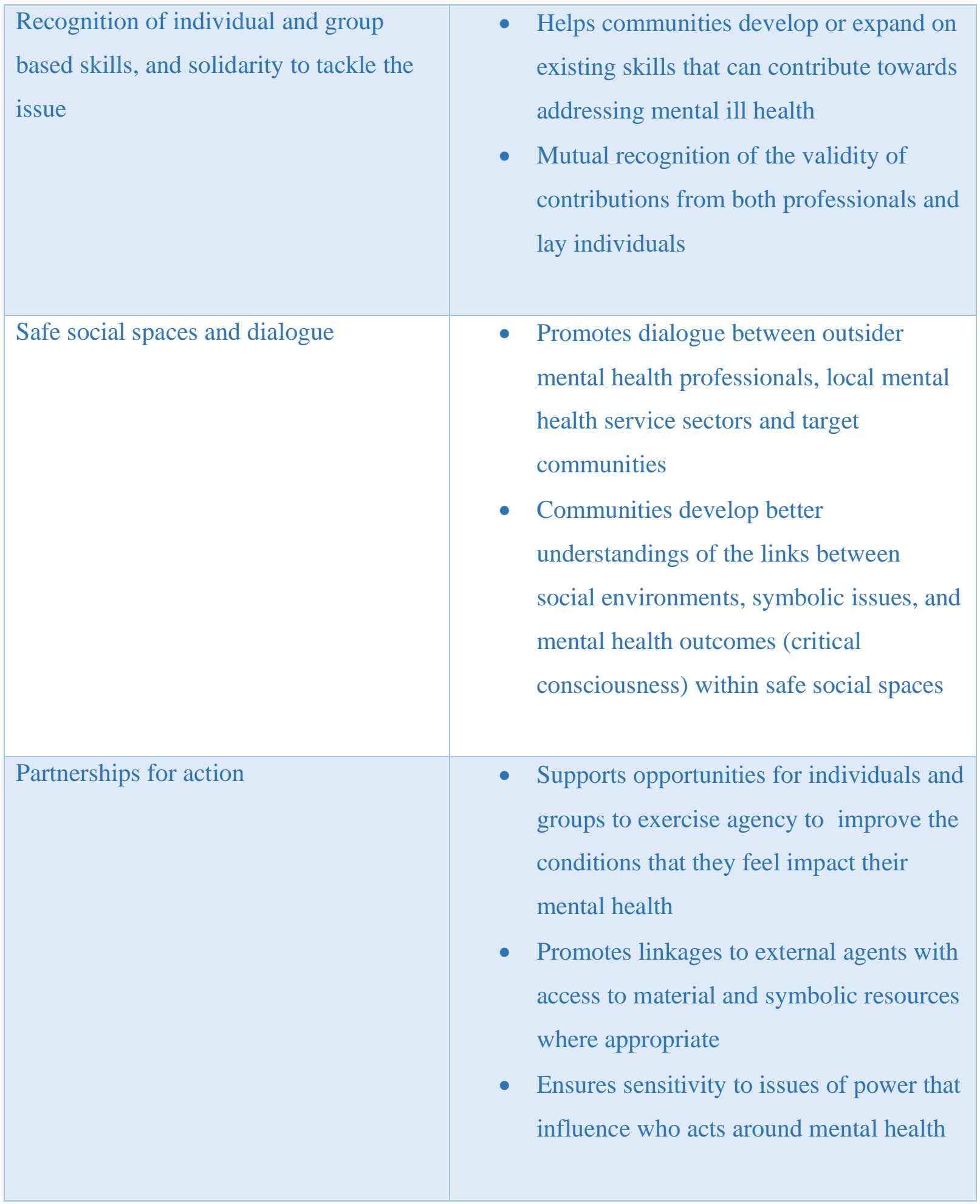

Table 1: Four Community mental health competencies (Burgess, 2013; Burgess, 2012; Campbell and Burgess, 2012)

The remainder of this chapter is organised around two case studies, each exploring how attention to community mental health competencies responds to mental ill health in locally relevant ways. The first case study explores the dimension of partnerships and knoweldge through a discussion of the inclusion of traditional healers in mental health 
services in a rural community mental health setting in South Africa. The second case study explores a partnership around a community mental health program in western Uttar Pradesh, India, and highlights the influence of key socio-structural challenges on attempts to establish competencies related to knowledge and safe social spaces. Cases draw on data in different ways - the first draws on analysis of a cluster of interviews with traditional healers, and the second on evaluation research and focus groups about the community mental health programme. 


\section{Traditional healers in South Africa-Knowledge without power}

\section{Background}

Though technically classified as a 'middle income country' - health services in South Africa are characterised by polarities, particularly within mental health services (Lund, Kleintjes, Kakuma, \& Flisher, 2010). Much of the country continues to struggle for access to basic amenities including electricity and running water, and is categorised as one of the most unequal in the world (Coovadia, Jewkes, Barron, Sanders, \& McIntyre, 2009)

The rural community at the heart of this case study is located in the province of KwaZulu Natal, just south of the Mozambique border. The province is one of the most underserved in terms of mental health services, marked by high levels of mental illness risk factors including a large proportion of individuals living below the poverty line (Burns, 2010). It is marked by high rates of HIV/AIDS (Welz et al. 2007) and high levels of unemployment (Statistics South Africa, 2006). Mental health services are delivered using a primary care approach (Department of Health, KwaZulu-Natal, 2003) within a district health model. The catchment area of focus is a rural sub-district with a population of just over 106,000 individuals (Department of Health, KwaZulu-Natal, 2010).

Flows of power and resources traverse multiple tiers of care. The 'community' is found at the base of the pyramid, who play a monitoring role, responsible for referring individuals up through the medical sectors (Department of health, KwaZulu-Natal,2003, p 11). The 'community' is comprised of multiple actors: NGOs, police officers, social workers, teachers, community-based organisations, community leaders, and spiritual and traditional healers. A larger case study completed by the first author featured a brief ethnographic study of this service model (See Burgess, 2013 for details). Semi-structured interviews with actors linked to the various communities engaged with mental health services in the sub-district were conducted. The subsequent discussion refers to data collected during life history interviews with traditional and spiritual healers, exploring their contributions to 'community' mental health services in the area.

South African traditional healing traditions are linked to notions of spirituality and reverence to ancestors (Berg, 2003; Parle, 2008). The role of the healer is to help restore balance between the self and various aspects of the individual's social world. In Kwa-Zulu Natal, illnesses are divided into natural conditions (linked to biomedical concerns) and those linked to ancestral discord. Typically natural conditions are initially treated by herbalists 
(Izinyangas). Long term illnesses are believed to have roots in ancestral disharmony, and as such, for chronic illnesses - such as mental health conditions, an Izangoma (spiritual healer) is often sought for support (Flint, 2008; Urbasch, 2002).

In this study, despite healers' description of mental illnesses along the traditional lines outlined above, their discussions also acknowledged that there were social and relational issues at the heart of distress. Two healers noted that in contemporary society - mental distress was linked to causes that they didn't understand fully. As noted by one healer:

During ancestral times it (mental illness) was there and it was caused by bewitchment - enemies bewitching people... But today we don't know because a lot of sicknesses today can cause mental illness. - Izangoma, Female 1

A long-standing body of research presents a discourse that positions traditional healer's involvement in mental health services as largely problematic. For example, Sorsdhal and colleagues (2010) recent study cite high numbers of deaths linked to traditional healers, and note the problematic use of potentially lethal combination of herbal medicines and toxic additives such as methane.

Healers interviews included descriptions of differential diagnosis process. They clearly parsed out differences in which those suffering from issues linked to more common mental disorders such as poverty and familial discord were supported, versus those with more severe conditions. Approaches to common mental health disorders did not include any of the more potentially harmful interventions that are critiqued by bio-medical practitioners. As one healer described:

Patients will often talk about things that are not well at home... like if someone can't sleep because they are having nightmares, or they don't have a job... this can all be caused by evil spirits. I take them outside for baths to cleanse away the evil spirits. _Izangoma, Male 2

Other treatment approaches included wrapping patients in 'blessed' pieces of cloth, as well as the process of 'throwing the bones' to explain the meaning behind client's experiences.

Despite plans to include traditional healers as partners within the delivery of mental health services from as early as 2003 , in practice this process has been fraught with difficulty given conflicting knowledge systems that drive traditional and formal health systems. This 
has often been linked to the negative attitudes held by many biomedical practitioners towards the methods and practices of healers (Urbasch, 2000). Despite current policy stipulations that call for partnerships with healers (Department of South Africa 2013), engagement between the two groups remains limited, and is shaped by continuing imbalances in power between the two groups. Healers in this study spoke of their experiences in partnering with formal health sectors, usually nurses, for training sessions. None of these engagements were for mental health (all had attended training on HIV/AIDS and TB). Their accounts noted unbalanced relationships with health services, attending sessions where they were told to explain how they made their medicines, with promises of further meetings with guidance on new treatments for their patients which never materialised. As noted by one healer:

We registered (with the doctors) and they told us that we will meet and talk about cases and treatment. We learned new things but they don't learn things from us - they asked us to cook our traditional medicine, and to tell them how we treat patients - but nothing has happened since then, because they take us for granted. We send patients to them when we cannot help them, but they don't send patients to us. -Iznagoma, M 1

Accounts from healers in this community highlight that main aim of the partnership remains as in the use of traditional healer's as extensions of the medical system - with little desire to engage in mutual frames of understanding and action. Healer's participation, and thus, the success of these partnerships, is influenced by dimensions of power and recognition (Burgess, 2014). When bio-medical systems are criticised by community members as 'brief or ineffective' by patients and family members, traditional healers can provide a seemingly positive alternative (Read, Adiibokah, \& Nyame, 2009). This means that in many cases, pluralism in service use is the prevailing norm - with patients utilising both traditional and biomedical services in tandem (Swartz, 1998). Accounts from healers in this study highlight that where partnerships with the health sector threaten the power of healers, or are interpreted as disrespectful to healer's training and knowledge, traditional healers will be reluctant to engage at all - limiting the utility of partnerships for both healers and formal practitioners. The result is a missed opportunity to increase the availability of support to communities through capacitating local healers to build on their existing set of responses to distress, as well as the alienation of key routes to access within local communities. 
The second case study presents an example of a combined partnership between communities and the formal health sector. The approach is informed by a rights based framework, attention to community empowerment, and increasing access to biomedical services for people with severe mental distress.

\section{Building community mental health competence in western Uttar Pradesh: Successes and challenges}

Background

SHIFA, a community mental health project of the large non-profit faith based organisation, the Emmanuel Hospital Association (EHA) (www.eha-health.org) started in April 2012 in Sadoli Kadim block (an administrative unit of around 150,000 people) in Saharanpur district, Uttar Pradesh (UP), at the upper reaches of the densely populated Gangetic plain. SHIFA is supported by an Australian community development funder, and had been supporting community health and development initiatives including community organisation, reproductive and child health and micro-credit savings groups in the SadoliKadim area in the previous nine years. They had moved to focus on promoting mental health and disability rights after building relationships with multiple families affected by disability and mental illness who described complete lack of access to care and support (Varghese, Mathias et al. 2015) and requested support from the project. Saharanpur is a relatively poor district with 3.5 million people (40\% Muslim, 60\% Hindu) and a literacy rate of $53 \%$. Health indicators for the district are lower than national and UP state averages. Western UP has been a recent flashpoint for communal violence (Bhatt 2013, Times of India 2014).

While a District Mental Health Programme (DMHP) was launched in India in the 1980's, it has been imperfectly and incompletely implemented across the country (Jain and Jadhav 2009, Sarin and Jain 2013). In Saharanpur district, there are no mental health services provided by the government, no psychologists and one private psychiatrist. The second author is linked to the project through her work as a mentor and technical advisor. The following discussion reports on data gathered through observational and support visits to the project, and interviews with people with mental distress and other community members.

At the start of the SHIFA project the biggest areas of felt need described by the community were for support to caregivers, knowledge, skills in mental health and access to care for people with mental distress. The community also described significant social exclusion and stigma for people with seizure disorders and mental distress. 
The overall vision of the SHIFA project was to empower communities of Sadoli-Kadim block, in the universal promotion of mental health. This included strengthening the community voice to advocate for care and support through the formation of community-based Disabled Persons Groups (DPGs), and increasing awareness and knowledge among 35 mental health volunteers and 140 trained peer educators. Further objectives were to strengthen the public health system through community monitoring and to increase access to primary mental health care, using the framework of the United Nations Convention for People with Disability (UNCRPD)(United Nations 2008). After 15 months of project implementation the SHIFA project started a fortnightly mental health clinic, led by the EHA psychiatrist and a primary care physician located nearby.

\begin{tabular}{|c|c|}
\hline Success factors & Challenges \\
\hline $\begin{array}{l}\text { Knowledge and awareness led to referral } \\
\text { networks and normalised } \\
\text { experiences(Petersen, Bailley et al. 2012) }\end{array}$ & $\begin{array}{l}\text { Scant engagement with socio- and structural } \\
\text { determinants of mental health }\end{array}$ \\
\hline $\begin{array}{l}\text { MHVs and PEs representative of minorities } \\
\text { in community enabled acceptance and } \\
\text { participation }\end{array}$ & $\begin{array}{l}\text { Lack of explicit training in conscientisation } \\
\text { for project staff and community volunteers }\end{array}$ \\
\hline $\begin{array}{l}\text { High commitment to training of community } \\
\text { volunteers seen in frequent trainings and } \\
\text { detailed curriculum }\end{array}$ & $\begin{array}{l}\text { Enduring social hierarchies and scant } \\
\text { 'horizontal dialogue'(Freire 1973, Campbell } \\
\text { and Jovchelovitch 2001) }\end{array}$ \\
\hline $\begin{array}{l}\text { Psychiatrist supporting resource } \\
\text { development, training and access to care }\end{array}$ & $\begin{array}{l}\text { Lack of confidence/ training / skills in } \\
\text { leading community discussions using rights- } \\
\text { based frameworks }\end{array}$ \\
\hline $\begin{array}{l}\text { Fortnightly clinic provided platform for } \\
\text { non-pharmacological therapy, awareness, } \\
\text { knowledge, street theatre and social } \\
\text { interaction }\end{array}$ & $\begin{array}{l}\text { Frequently changing government } \\
\text { functionaries and lack of will in district } \\
\text { health officers to provide access to services } \\
\text { for people with mental distress }\end{array}$ \\
\hline $\begin{array}{l}\text { Care plan prioritised felt needs of client } \\
\text { increasing their agency and participation }\end{array}$ & \\
\hline
\end{tabular}

Table 2: Success factors and challenges in building community mental health competencies in Shifa project, Uttar Pradesh

\section{Knowledge}


Focus groups held at the outset of the project identified that some people understood seizure and severe mental distress as being caused by an evil spirit or by 'black' magic. Other community members considered severe mental distress as a stress reaction to life events or as an illness. A total of 35 community Mental Health Volunteers (MHVs) were selected by their communities and worked in their respective panchayat (administrative unit of around 2000 people) with the aim to build awareness and knowledge about mental health in the community. 140 adolescent peer educators (PEs) were selected as the community members with most available time. All volunteers were trained in basic knowledge and skills for mental health promotion such as in rights based approaches, stress management, and communication skills. There was a significant increase in biomedical mental health related knowledge and skills, such as the ability to identifying and differentiate common and severe mental distress, particularly among the 175 community volunteers. Caregivers reported increased skills in areas such as reflective listening and problem-solving. Peer educators reported increased confidence to speak out in schools and community gatherings, particularly in areas related to rights, health and relationships. Increased knowledge led to changes in help seeking behaviour. By the end of March 2015 community volunteers and staff working with SHIFA had identified and provided social and psychological support, treatment or referral to 150 people with common mental distress, 70 people with a severe mental distress, 35 people with a seizure disorders and 13 people with intellectual disability(Kamal 2015). Around one third of these people regularly attended the SHIFA primary mental care clinic held fortnightly. There were also reports of increased attendance for support with mental distress by local pharmacists, traditional healers and local doctors. Workshops held by project staff with religious leaders, traditional healers and local doctors focussed on building their knowledge and skills in active listening and encouraging referral of people with seizure disorders and severe mental disorders to the biomedical health clinic while their clients continued to also access their services.

\section{Safe social spaces}

While some dialogue and critical thinking about mental health occurred between mental health volunteers and peer educators, they themselves struggled to facilitate critical discussions in wider community settings. Stigma was a completely obstructive barrier to the inclusion of people with mental disorders in community-based Disabled Persons Groups. While ten DPGs were formed, they were fully comprised of people with physical or sensory deficits and people with both common and severe psycho-social disabilities were excluded. 
SHIFA however did make some small gains to amplify safe social spaces for people with seizure disorders by facilitating open discussion among community members as well as providing access to medical care. A mother from one community reported that her child who had been socially ostracised by neighbours due to her frequent seizures, became fully engaged in school and social life following medical treatment to manage her seizures.

\section{Developing partnerships}

Some progress was made by community members working collaboratively and with outside groups to increase resources for mental health in their community. Through training and information, community members with both physical and psycho-social disabilities increased access to Government entitlements. 263 people accessed Disability certificates and 126 people started on the Disability Pension. Another example of an evolving partnership was the invitation to SHIFA to run their mental health clinic in the Government community health centre.

\section{Challenges}

Despite successes in the above areas, the SHIFA project struggled to increase the availability of safe social spaces as opportunities for 'critical thinking'. Four main factors impacted on this process in the following ways. Firstly, a lack of confidence and skills in leading critical discussions within a rights based framework lead to an inability to deliver discussion groups at the project level. Despite EHA's progression towards a rights based frameworks since 2010 , the majority of staff and community volunteers were not formally trained in a critical thinking framework.

Secondly, deeply embedded social hierarchies and divisions in Uttar Pradesh complicated wider community engagements. Social divisions were reflected in the recent Saharanpur district communal violence in July 2013 and January 2014 between religious groups. Government health officers, community health volunteers and community members all had multiple discussions with the second author expressing prejudice and mistrust of members of religious traditions different to their own. Community members described divides of caste, socio-demographic status and particularly religion as restricting collaborative initiatives.

Third, there were few historical precedents of successful community action that could serve as a foundation or collective memory for community members. There is a sparse history of community agency, and action in any areas impacting quality of life in Saharanpur district. 
For example, there are almost no accounts of collaborative community action on overt failures of public services such as poor roads, teachers absenteeism in Government schools, absence of essential drugs and nutritional support for malnourished children at primary health clinics (Dreze and Sen 2013).

Finally, prevalent gendered hierarchies and exclusion of women, and people of Muslim faith was evident and a stumbling block for wider community engagement. These groups respectively comprise $50 \%$ and $40 \%$ of the population but have disproportionately low representation in nearly all public positions and are widely recognised as excluded and disadvantaged (World Economic Forum 2009, Dreze and Sen 2013, Hassan 2013). In this prevailing masculine hegemony, women are overtly excluded from most decision making and rarely make decisions on even household food expenditure. People with mental distress are also socially excluded, at times violently. Recent qualitative research in Sadoli-Kadim block and another western Uttar Pradesh district describes experiences of exclusion and inclusion for people with mental distress. It illustrates complicated communities where both social exclusion and inclusion are strong features of the lives of people with mental distress. Experiences of derision, disinheritance and physical violence against people with mental distress were contrasted against experiences of belonging, opportunity for participation and high levels of practical support from neighbours (Mathias, Kermode et al. 2015).

Many of the successes of the first phase of SHIFA project suggest that a strong community representation with both peer educators and MHVs create a strong foundation for expanding safe social spaces and partnerships. Opportunities for future growth reside in capacity building of community members and SHIFA staff to increase skills in facilitating critical thinking about wider social determinants at both organisational and community levels.

\section{Discussion}

Despite the renewed attention 'community' has garnered within the movement for global mental health, the question of what communities need for the promotion of mental health and well-being is a long standing concern in the fields of health promotion and community development. These case studies have highlighted the importance of complicating the term' community' in global mental health approaches. In each case we see that 'community' mental health services include a range of actors from traditional healers, to district level hospitals to service users or rejecters, and members of a wider shared geographical community who contribute to the promotion of mental health. 
Case studies have highlighted the importance of knowledge, community identity and partnerships as key symbolic phenomena that may sway the success of community health mental health interventions. Beyond this, the ongoing importance of attention to social determinants, partnerships with more powerful stakeholders, and collective action by communities to address the realities that impact on their health remain important areas for further engagement.

The SHIFA project made significant progress in increasing community knowledge about mental health issues, and made some attempts to engage with pre-existing local knowledge about mental health. However, the project struggled to significantly increase safe social spaces and collaborative community action to develop partnerships. The Community Mental Health Competency framework offers possible routes forward from this impasse. A conscientisation process which acknowledges and engages with structures driving social exclusion, such as the prevailing gender order of hegemonic masculinity (Connell 2012) could potentially provide a route to bring excluded minority groups within wider community participation For example, a recent study of effective community monitoring of health services in Maharashtra highlighted that development of critical thinking contributed to the development of safe spaces (Shukla, Saha et al. 2013), and could be applied similarly within the Sadoli-Kadim community to promote collective action.

Traditional healers in South Africa highlight the importance of attending to issues of knowledge and power in establishing key partnerships for the promotion of mental wellbeing. The views of traditional healers in this study illuminate a gap in current engagements with healers, particularly around valuing the knowledge held by this community, and a recognition of their expertise and ability to meaningfully contribute to care. Within Global Mental Health, what counts as knowledge is often that which is produced by 'science', driven by calls for increased randomised controlled trials to determine next steps in treatment and care (Patel et al., 2011). This emphasis has been argued as problematic, a form of engagement that produces socially de-contextualised understandings of mental ill-health, with limited attention to the impacts of cultural understandings of distress that exist within various communities (Summerfield 2008). Furthermore, such approaches have been criticised for their inability to grapple with the complexity of community realities that also shape services (Burgess, 2015; Rifkin, 2014; Pawson, Greenhalgh, Harvey \& Walshe, 2005). This emphasis on production of rational scientific knowledge diverts attention from the value to be found within indigenous knowledge systems, and reifies a binary between biomedicine and 
'lay knowledge' within mental health. However, given the growing evidence of plurality of modalities of care for many users (Halliburton, 2004), attention to how the knowledge held by groups like healers can better contribute to treatment is critical for community service models to be truly representative of community needs.

Both case studies shed light on the importance of attending to structural realities imposed by communities of 'place' to improve community mental health. In South Africa, the history of segregation and limited power surrounding traditional healers is linked to the problematic insertion of this group of actors into the community mental health system as 'equals'. In India, the existing structures maintained exclusion for people with mental distress from Disabled Persons Groups and no group or person felt confident to address these.

The value of partnerships was reinforced by both case studies. Partnerships have been linked to positive health outcomes by many theorists. For example, Campbell and Burgess (2012) argue that the MGMH's network of global partners with access to economic (funding) and political (policy leverage) forms of capital, creates potential nodes for local community actors to leverage efforts to transform their local environments. Some positive gains have been witnessed in these areas, as seen for example with the Zambian mental health service user organisations who through links to the MGMH movement have been able to successfully lobby the national government to repeal outdated legislation (WHO, 2010). However, there are fewer examples of how every day community members are able to leverage and participate in global networks, with genuine engagements between local and global actors rarely seen.

Though exploring dimensions of a community mental health competency approach, the importance of promoting 'receptive social environments' for mental health emerges. In the case of the SHIFA case study, the need to target broader gender driven norms to ensure equal participation in the use of knowledge is one example of this need. In the Icarus project, users create their own receptive environments by moving out of collaboration with conflicting partners and ideals entirely, within private online spaces. In South Africa, negative views among biomedical practitioners towards traditional healers limit the establishment of a receptive space. Receptive social environments in service spaces could be facilitated through attention to Woolcock's (1998) notions of 'linking' social capital, defined as partnerships that utilise brokers able to move between local community and external resources. Brokers effectively speak both 'languages' to facilitate the transfer of resources to 
local levels, by moving across multiple spheres, helping to translate key messages between community members who have shared interests (Cornish et al., 2012). This approach could permit the development of more meaningful partnerships between traditional healers and mental health services in South Africa by increasing trust and understanding between these groups.

\section{Conclusion}

Despite the complexities of implementing participation, dialogue and critical consciousness, the relevance of a framework for community mental health in the contexts of a global movement for mental health remains. Each case study highlights a different way of viewing community - a collection of partnerships engaged in a shared activity of developing a service, and as a specific group of individuals (healers) who need to be engaged in order to promote better services in a community of place. In each case, we see that through exploring the presence or absence of certain competencies, engagements and activates in varied communities are either helped or hindered. We also see the need for thinking about routes to accessing power - something that is enabled through links to wider groups and agents for action.

As asserted by Campbell and colleagues (2012b) global partnerships for health are not to be fully discounted, as they provide communities with gateway access to much needed resources. For example, providing countries like South Africa with a solid platform to advocate with national governments for increasing budgetary allocations and services for mental health to address what is an undeniable level of need. However, these relationships have also been critiqued for promoting representations of mental health that remain at odds with local understandings and experiences of distress (Campbell, et al., 2012b; Seckinelgin, 2006) and often solidify top-down flows of power and resources that may potentially only further marginalise communities who struggle to manage socially disparate contexts (Aveling, 2010). The promotion of community competencies implies an acceptance of the positive potential of such these partnerships: their proxy for access to resources and empowerment. If global mental health programmes were designed with the view of communities as active agents, then opportunities for engagement that that drive community visions of mental-wellbeing forward would be at the heart of efforts. Such an approach ultimately transfer decision making power about definitions and responses to mental ill health away from high income countries and to the hands of communities themselves. Whether the 
global movement sees such efforts as a fruitful way forward, remains to be seen, but regardless, may provide our best hope for truly achieving mental health for all, in whatever iteration that may take. 
References

Allen, J., Balfour, R., Bell, R., \& Marmot, M. (2014). Social determinants of mental health. Int Rev Psychiatry, 26(4), 392-407. doi:10.3109/09540261.2014.928270

Aveling, E. L. (2010). The impact of aid chains: relations of dependence or supportive partnerships for community-led responses to HIV/AIDS? AIDS Care, 22(sup2), 15881597.

Berg, A. (2003). Ancestor reverence and mental health in South Africa. Transcult Psychiatry, 40(2), 194-207.

Bhatt, V. (2013). What led to the Muzaffarnagar communal riots. Tehelka.

Bourdieu, P. (1986). The forms of capital, In J. Richardson (Ed.), Handbook of Theory and Research for the Sociology of Education (pp. 241-248). New York: Greenwood.

Burgess, R. (2015, in press). Policy, power, stigma silence: exploring the complexities of a primary mental health care model in a rural South African setting. Transcultural Psychiatry

Burgess, R. A. (2013). "It Depends on Them" - Exploring Order and Disjuncture in Responding to the Local Needs of AIDS Affected Communities in the Kingdom of Swaziland. The Journal of Development Studies, 50(4), 467-480. doi:10.1080/00220388.2013.858123

Burgess, R. A. (2013). Supporting "community" in an era of global mental health: a case study of an HIV-affected South African community. Retrieved from http://etheses.lse.ac.uk/808/1/Burgess_supporting_community_global_mental_health_ (public).pdf

Burgess, R. A. (2014). Supporting mental health in South African HIV-affected communities: primary health care professionals' understandings and responses. Health Policy and Planning, 1-11. doi:10.1093/heapol/czu092

Burgess, R., \& Campbell, C. (2014). Contextualising women's mental distress and coping strategies in the time of AIDS: A rural South African case study. Journal of Transcultural Psychiatry, 51(6), 875-903.

Burns, J. K. (2010). Mental health services funding and development in KwaZulu-Natal: a tale of inequity and neglect. S Afr Med J, 100(10), 662-666.

Campbell, C. (2000). Selling sex in the time of AIDS: the psycho-social context of condom use by sex workers on a Southern African mine. Social Science \& Medicine, 50(4), 479-494. doi:10.1016/S0277-9536(99)00317-2

Campbell, C., \& Burgess, R. (2012). The role of communities in advancing the goals of the Movement for Global Mental Health. Transcultural Psychiatry, 49(3-4), 379-95. doi:10.1177/1363461512454643

Campbell, C., Cornish, F., \& Skovdal, M. (2012b). Local pain, global prescriptions? Using scale to analyse the globalisation of the HIV/AIDS response. Health and place, 18(3), 447-452.

Campbell, C., \& Cornish, F. (2010). Towards a "fourth generation" of approaches to HIV/AIDS management: Creating contexts for effective community mobilisation. 
Aids Care-Psychological and Socio-Medical Aspects of Aids/Hiv, 22(S2), 15691579.

Campbell, C., Gibbs, A., Maimane, S., \& Nair, Y. (2008). Hearing community voices: grassroots perceptions of an intervention to support health volunteers in South Africa. Sahara J-Journal of Social Aspects of Hiv-Aids, 5, 162-+.

Campbell, C., \& Nair, Y. (2014). From rhetoric to reality? Putting HIV and AIDS rights talk into practice in a South African rural community. Culture, Health \& Sexuality. 16(10), 1216-1230. doi:10.1080/13691058.2014.930180

Campbell, C. and S. Jovchelovitch (2001). Health, Community and Development: toward a social psychology of participation. Journal of Community and Applied Social Psychology 10: 255-270.

Cohen, A. (1985). The symbolic construction of community. Routledge.

Connell, R. (2012). "Gender, health and theory : conceptualizing the issue, in local and world perspective." Social Science and Medicine 74 1675-1683.

Coovadia, H., Jewkes, R., Barron, P., Sanders, D., \& McIntyre, D. (2009). The health and health system of South Africa: historical roots of current public health challenges. Lancet, 374(9692), 817-34. doi:10.1016/S0140-6736(09)60951-X

Cornish, F., Campbell, C., Shukla, A., \& Banerji, R. (2012). From brothel to boardroom: Prospects for community leadership of HIV interventions in the context of global funding practices. Health \& Place, 18(3), 468-474. doi:10.1016/j.healthplace.2011.08.018

Department of Health South Africa (2013). National Mental Health Policy Framework and Strategic Plan (2013-2020). Accessed online (08.01.2015) http://www.healthe.org.za/wp-content/uploads/2014/10/National-Mental-Health-Policy-Frameworkand-Strategic-Plan-2013-2020.pdf

Department of Health KwaZulu-Natal (2003). Strategic and implementation plan for delivery of mental health services in KwaZulu-Natal. Department of Health, South Africa.

Department of Health KwaZulu-Natal (2010). Manguzi Hospital information. Accessed online: http://www.kznhealth.gov.za/manguzihospital.htm

Dreze, J. and A. Sen (2013). An uncertain glory : India and its contradictions. New Delhi, Penguin.

Flint, K. E. (2008). Healing traditions : African medicine, cultural exchange, and competition in South Africa, 1820-1948. Athens; Ohio; Scottsville, SA: Ohio University Press

Fraser, N. (1990). Rethinking the public sphere: A contribution to the critique of actually existing democracy. Social Text, 25, 56-80.

Freire, P. (1973). Education for Critical Consciousness. New York: Continuum.

Fremeaux, I. (2005). New Labour's appropriation of the concept of community: a critique. Community Development Journal, 40(3), 265-274.

Fullagar, S., \& O'Brien, W. (2014). Social recovery and the move beyond deficit models of depression: a feminist analysis of mid-life women's self-care practices. Social Science \& Medicine (1982), 117, 116-24. doi:10.1016/j.socscimed.2014.07.041 
Gibbs, A., \& Campbell, C. (2014). Social Contexts and Building Social Capital for Collective Action: Three Case Studies of Volunteers in the Context of HIV and AIDS in South Africa. Journal of Community \& Applied Social Psychology. 25 (2): 110-122

Habbermas, J. (1984). The theory of communicative action, vol 1: Reason and the rationalization of society. Boston: Beacon Press.

Hanlon, C., Luitel, N. P., Kathree, T., Murhar, V., Shrivasta, S., Medhin, G., ... Prince, M. (2014). Challenges and opportunities for implementing integrated mental health care: a district level situation analysis from five low- and middle-income countries. PloS One, 9(2), e88437. doi:10.1371/journal.pone.0088437

Hanlon, C., Wondimagegn, D., \& Alem, A. (2010). Lessons learned in developing community mental health care in Africa. World Psychiatry: Official Journal of the World Psychiatric Association (WPA), 9(3), 185-9. Retrieved from http://www.pubmedcentral.nih.gov/articlerender.fcgi?artid=2948731\&tool=pmcentrez \&rendertype $=$ abstract

Hassan, S. (2013). Muslim exclusion in India: a review of the literature. New Delhi, Centre for Equity Studies, New Delhi.

Howarth, C. S. (2001). Towards a social psychology of community: A social representations perspective. Journal for the Theory of Social Behaviour, 31(2), 223-238.

Howarth, C., Cornish, F. \& Gillespie, A. (2014). Making communities: Diversity, movement and interdependence. In G. Sammut, E. Andreouli, G. Gaskell \& J. Valsiner (Eds), Handbook of Social Representations. Cambridge: Cambridge University Press.

Jain, S. and S. Jadhav (2009). "Pills that swallow policy: clinical ethnography of a community health program in North India." Transcultural Psychiatry 46(60).

Jovchelovitch, S. (2007). Knowledge in context. London: Routledge.

Kakuma, R., Minas, H., van Ginneken, N., Dal Poz, M. R., Desiraju, K., Morris, J. E., ... Scheffler, R. M. (2011). Human resources for mental health care: current situation and strategies for action. Lancet, 378(9803), 1654-63. doi:10.1016/S01406736(11)61093-3

Kamal, R. (2015). Annual report - SHIFA community mental health project. C. H. a. D. p. EHA. New Delhi, India, Emmanuel Hospital Association.

Kirmayer, L., \& Pedersen, D. (2014). Toward a new architecture for global mental health. Transcultural Psychiatry. Retrieved from http://tps.sagepub.com/content/51/6/759.short

Kleinman, A. (1988). Rethinking psychiatry. New York: Free Press.

Knapp, M., Beecham, J., McDaid, D., Matosevic, T., \& Smith, M. (2011). The economic consequences of deinstitutionalisation of mental health services: lessons from a systematic review of European experience. Health \& Social Care in the Community, 19(2), 113-25. doi:10.1111/j.1365-2524.2010.00969.x

Lowndes, V., \& Pratchett, L. (2012). Local Governance under the Coalition Government: Austerity, Localism and the "Big Society." Local Government Studies, 38(1), 21-40. 
Lund, C., Kleintjes, S., Kakuma, R., \& Flisher, A. J. (2010). Public sector mental health systems in South Africa: Inter-provincial comparisons and policy implications. Social Psychiatry and Psychiatric Epidemiology, 45, 393-404. doi:10.1007/s00127-0090078-5

Mathias, K., K. Kermode, M. San Sebastian, M. Korschorke and I. Goicolea (2015). "Under the banyan tree - exclusion and inclusion of people with mental distress in rural North India." (Forthcoming).

Nelson, G., \& Prilleltensky, I. (2010). Community psychology. 2nd Ed. Houndmills, Basingstoke, Hampshire: Palgrave Macmillan.

Parle, J. (2007). States of Mind: Searching for Mental Health in Natal and Zululand, 18681918: University of Kwazulu Natal Press.

Patel, V., Boyce, N., Collins, P. Y., Saxena, S., \& Horton, R. (2011). A renewed agenda for global mental health. Lancet, 378(9801), 1441-2. doi:10.1016/S0140-6736(11)613858

Patel, V., \& Prince, M. (2010). Global Mental Health. JAMA: Journal of the American Medical Association, 303, 1976-1977. Retrieved from http://search.ebscohost.com/login. aspx?direct=true \&db=hch\&AN=50833741\&site=e host-live

Pawson, R., Greenhalgh, T., Harvey, G., \& Walshe, K. (2005). Realist review - a new method of systematic review designed for complex policy interventions. Journal Of Health Services Research \& Policy, 10(suppl 1), 21-34. doi:10.1258/1355819054308530

Petersen, I., Bhana, A., Campbell-Hall, V., Mjadu, S., Lund, C., Kleintjies, S., ... Flisher, A. J. (2009). Planning for district mental health services in South Africa: A situational analysis of a rural district site. Health Policy and Planning, 24, 140-150. doi:10.1093/heapol/czn049

Petersen, I., K. Bailley, A. Bhana and et al (2012). "Understanding the benefits and challenges of community engagement in the development of mental health services for common mental disorders: lessons from a case study in a rural South African subdistrict site." Transcultural Psychiatry 49(3-4): 418-437.

Read, U. M., Adiibokah, E., \& Nyame, S. (2009). Local suffering and the global discourse of mental health and human rights: an ethnographic study of responses to mental illness in rural Ghana. Globalization and Health, 5, 13. doi:10.1186/1744-8603-5-13

Rifkin, S. (2014). Examining the links between community participation and health outcomes: a review of the literature. Health Policy And Planning, 29(suppl 2), ii98ii106. doi:10.1093/heapol/czu076

Rose, V., \& Thompson, L. (2012). Space, place and people: a community development approach to mental health promotion in a disadvantaged community. Community Development Journal, 47(4), 604-611. doi:10.1093/cdj/bss024

Sarin, A. and S. Jain (2013). "The 300 Ramayanas and the District Mental Health Plan." Economic and Political Weekly 153(25): 77-81.

Saxena, S., Thornicroft, G., Knapp, M., \& Whiteford, H. (2007). Resources for mental health: scarcity, inequity, and inefficiency. Lancet, 370(9590), 878-89. doi:10.1016/S01406736(07)61239-2 
Seckinelgin, H. (2006). The international politics of HIV/AIDS: global disease-local pain. London: Routledge.

Shukla, A., S. Saha and N. Jadhav (2013). Community-based planning and monitoring in Maharashtra - a case study. SATHI. Pune, India, COPASAH.

Sorsdahl, K., Stein, D. J., \& Flisher, A. J. (2010). Traditional Healer Attitudes and Beliefs Regarding Referral of the Mentally Ill to Western Doctors in South Africa. [Article]. Transcultural Psychiatry, 47(4), 591-609.

Statistics South Africa (2006). General Household Survey 2006: Metadata/Statistics SouthAfrica. Pretoria: Statistics South Africa, 2007

Summerfield, D. (2012). Afterword: Against "global mental health". Transcultural Psychiatry, 49(3-4), 519-530. doi:10.1177/1363461512454701

Summerfield, D. (2008). How scientifically valid is the knowledge base of global mental health? BMJ: British Medical Journal, pp. 992-994. Retrieved from http://search.ebscohost.com/login.aspx?direct=true $\& d b=h c h \& A N=32005705 \&$ site $=e$ host-live

Swartz, L. (2012). An unruly coming of age: The benefits of discomfort for global mental health. Transcultural Psychiatry, 49(3-4), pp.531-538.

Swartz, L. (1998). Culture and mental health: A southern African view. Cape Town South Africa: Oxford University Press Southern Africa.

Times of India (2014). Saharanpur communal riots: 20 arrested, curfew 'strictly implemented. Times of India. Lucknow, Uttar Pradesh, Times of India.

United Nations (2008). United Nations Conventions on the Rights of Persons with Disabilities. Geneva.

Urbasch, M. (2002). African traditional healing systems: Representations and restitutions, In V. Faure (Ed.), Bodies and Politics: Healing rituals in the Democratic South Africa (pp. 5-23): Les Cahiers de l' IFAS n2.

Varghese, J., K. Mathias and N. Grills (2015). "Barriers in health care access for children with intellectual disabilities living in rural Uttar Pradesh." Forthcoming.

Weinstein, L. C., Lanoue, M. D., Plumb, J. D., King, H., Stein, B., \& Tsemberis, S. (2013). A primary care-public health partnership addressing homelessness, serious mental illness, and health disparities. Journal of the American Board of Family Medicine : JABFM, 26(3), 279-87. doi:10.3122/jabfm.2013.03.120239

Welz, T., Hosegood, V., Jaffar, S., Bätzing-Feigenbaum, J., Herbst, K., \& Newell, M.-L. (2007). Continued very high prevalence of HIV infection in rural KwaZulu-Natal, South Africa: a population-based longitudinal study. AIDS, 21(11), 1467-1472

Whiteford, H. A., Degenhardt, L., Rehm, J., Baxter, A. J., Ferrari, A. J., Erskine, H. E., ... Vos, T. (2013). Global burden of disease attributable to mental and substance use disorders: findings from the Global Burden of Disease Study 2010. Lancet, 382(9904), 1575-86. doi:10.1016/S0140-6736(13)61611-6 
WHO. (2010). mhGAP intervention guide for mental, neurological and substance use disorders in non-specialized health settings: mental health Gap Action Programme (mhGAP). Geneva: World Health Organization.

World Economic Forum (2009). Global Gender Gap report, World Economic Forum.

Woolcock, M. (1998). Social capital and economic development: Toward a theoretical synthesis and policy framework. Theory and society, 27(2), 151-208.

Author Acknowledgements:

RB: Thanks to the editors of the volume for their patience with the production of this chapter. Many thanks to my partner EJR for his patience, kindness and support with editing the work of a verbose academic. To the healers who contributed their time and commitment to the study, in hope for better services for their communities: My deepest and most heartfelt thanks.

KM: Thanks to all the many community Mental Health Volunteers and community members of Sadoli-Kadim and people and families living with mental distress who have walked this road with us thus far. Appreciation also to Raj Kamal, Somesh Pratap Singh, Robert Kumar, Jubin Varghese, the EHA CHDP team and the SHIFA team: Bharosa, Rajeev, Nitay, Janaki, Sandra and Vimala as members of the SHIFA team who continue to engage, discuss and support all our efforts to think aloud and build community mental health in Sadoli-Kadim block, Saharanpur, Uttar Pradesh. 